\title{
PENERAPAN APLIKASI PENJUALAN ONLINE (E-COMMERCE) MENGGUNAKAN CONTENT MANAGEMENT SYSTEM WORDPRESS PADA TOKO JAKSQUARE
}

\author{
Rizky Dharmawan ${ }^{1)}$, Grace Gata ${ }^{2)}$ \\ ${ }^{1}$ Sistem Informasi, Fakultas Teknologi Informasi, Universitas Budi Luhur \\ 1,2 Jl. Raya Ciledug, Petukangan Utara, Kebayoran Lama, Jakarta Selatan 12260 \\ E-mail : rizkydarmawann97@gmail.com ${ }^{1)}$, grace.gata@budiluhur.ac.id ${ }^{2}$ )
}

\begin{abstract}
Abstrak
Perkembangan Electronic Commerce (E-Commerce) membawa banyak perubahan terhadap sektor aktivitas bisnis yang selama ini dijalankan di dunia nyata. Perubahan tersebut merubah semua kegiatan marketing dan juga sekaligus memangkas biaya-biaya operasional untuk kegiatan perdagangan tanpa harus datang ke tempatnya dan diartikan sebagai proses pembelian, penjualan produk dan informasi yang dilakukan secara elektronik dengan memanfaatkan komputer. Penelitian ini mengambil studi kasus pada toko Jaksquare yaitu toko resmi The Jakmania atau pendukung tim sepak bola Persija Jakarta yang bergerak didalam bidang fashion yang menjual berbagai macam pakaian dan aksesoris tim sepak bola Persija Jakarta. Sistem penjualan pada toko Jak Square untuk saat ini dalam pemasarannya hanya melalui media sosial dan dalam pembuatan laporan yang dilakukan masih berupa pembukuan, dimana pemilik toko masih kurang teliti dalam melakukan pencatatannya. Tujuan dari penelitian ini adalah menerapkan aplikasi penjualan online (E-Commerce) menggunakan Content Management System (CMS) yaitu Wordpress. Penilitian ini menggunakan metode Bussines Model Canvas (BMC) yang memudahkan toko untuk menentukan strategi bisnis ke depannya dan membantu dalam kelangsungan produksi dan penjualannya. Hasil dari penelitian ini adalah menerapkan website E-Commerce untuk mempermudah pelanggan dalam melakukan transaksi tanpa adanya batasan waktu dan tempat, serta dapat membantu toko Jak Square dalam meningkatkan penjualan dan pemasaran produknya.
\end{abstract}

Kata kunci: E-Commerce, Content Management System, Bussines Model Canvas, Persija.

\section{PENDAHULUAN}

\subsection{Latar Belakang}

Perkembangan teknologi yang sudah merambah ke segala sisi kehidupan manusia membuat banyak orang yang memanfaatkannya untuk hal-hal yang berbau ekonomi. Teknologi dan kecanggihan internet saat ini benar-benar membantu manusia dalam memenuhi kebutuhannya. Seperti para inovator yang memanfaatkannya sebagai sarana penjualan segala kebutuhan manusia. Aspek yang boleh dibilang utama dalam perkembangannya adalah munculnya E-commerce yang akan merubah semua kegiatan marketing dan juga sekaligus memangkas biaya-biaya operasional untuk kegiatan perdagangan tanpa harus datang ke tempatnya dan diartikan sebagai proses pembelian, penjualan produk dan informasi yang dilakukan secara elektronik dengan memanfaatkan komputer[1].

Jak Square adalah toko resmi The Jakmania atau pendukung tim sepak bola Persija Jakarta yang berlokasi di Jl. Joglo Raya No. 38 Jakarta Barat. Toko ini adalah salah satu usaha yang bergerak didalam bidang fashion, yang menjual berbagai macam pakaian dan aksesoris tim sepak bola Persija Jakarta. Berdasarkan riset yang telah penulis lakukan, sistem pemasaran toko Jak Square untuk saat ini hanya melalui media sosial seperti instagram dan facebook, akibatnya tidak banyak diketahui oleh calon customer yang membuat menurunnya penjualan karena persaingan yang semakin terus bertambah, dan laporan penjualan yang dilakukan pada toko ini berupa pembukuan yang mengakibatkan pemilik toko seringkali masih kurang teliti dalam melakukan pencatatan produk yang terjual.

\subsection{Permasalahan}

Berikut identifikasi masalah berdasarkan latar belakang:

a) Kurang sarana promosi untuk memasarkan produk, sehingga tidak banyak diketahui oleh calon customer.

b) Sulit untuk menginformasikan mengenai produk terbaru, dan kurangnya sarana promosi untuk meningkatkan penjualan.

\subsection{Tujuan Dan Manfaat Penulisan}

a. Tujuan Penulisan

1) Mempermudah pelaku usaha dalam memasarkan produknya sehingga toko dapat dikenal masyarakat luas serta dapat meningkatkan pendapatan penjualan.

2) Memudahkan pelaku usaha dalam menginformasikan produk terbaru kepada 
customer.

b. Manfaat Penulisan

1) Syarat kelulusan serta menambah wawasan dan pengetahuan.

2) Diharapkan dapat membantu toko Jak Square ini dalam meningkatkan penjualan dari sebelumnya.

\subsection{Content Management System (CMS)}

CMS adalah sebuah aplikasi website yang bersifat generik dalam arti telah memiliki sejumlah fitur yang dapat diaktifkan dan dimanipulasi sesuai kebutuhan pengguna dan dapat digunakan dengan mudah tanpa mensyaratkan keahlian pemrograman[2].

\subsection{Wordpress}

WordPress adalah sebuah aplikasi content managemant sistem ( CMS ) berbasis web yang dibuat dengan bahasa pemrograman PHP dan Mysql sebagai basis datanya. CMS ini merupakan salah satu contoh aplikasi open source yang banyak diminati oleh pemilik website karena kemampuannya dalam memodifikasi yang dapat membangun sebuah situs pribadi, perusahaan, situs blog bahkan ecommerce dengan hanya hitungan menit, dengan hasil yang cukup memuaskan[2].

\subsection{Business Model Canvas (BMC)}

Business Model Canvas merupakan Kerangka model bisnis yang berbentuk kanvas dan terdiri dari sembilan blok yang berisikan elemen-elemen yang saling berkaitan, bagaimana organisasi menciptakan manfaat dan mendapatkan manfaat bagi dan dari pelanggannya[3].

\subsection{Penelitian Sebelumnya}

Dari penelitian yang telah dilakukan oleh[4] dengan judul "Rancang Bangun Sistem Informasi ECommerce Untuk Usaha Fashion Studi Kasus Omah Mode Kudus”. Omah Mode Kudus merupakan salah satu toko di kota Kudus yang bergerak di bidang fashion, seperti : baju celana, topi, jaket, kaos, sweater dan lainnya. Namun, dengan sistem yang berjalan sekarang, masih banyak masalah yang terjadi baik di pihak vendor maupun di pihak konsumen terutama yang berada di luar kota Kudus. Pihak vendor selama ini belum memiliki media khusus untuk mempromosikan produk-produknya. Dan konsumen masih harus langsung datang ke toko apabila ingin mendapatkan informasi produk dan hendak memesan produk sesuai dengan yang diinginkan, serta konsumen harus menghubungi vendor via sms / telepon jika ingin mengetahui perkembangan stok, koleksi terbaru. Oleh karena itu peneliti membuat aplikasi E-commerce yang dapat membantu pihak vendor untuk mempromosikan produknya dan mempermudah dalam pengelolaan E-commerce yang dimiliki. Peneliti menggunakan metode waterfall karena tahap demi tahap yang dilalui harus menunggu selesainya tahap sebelumnya dan berjalan berurutan. Tujuan dari penelitian ini adalah menghasilkan, simulator toko online factory outlet, menghasilkan reporting untuk setiap transaksi penjualan, dan juga menghasilkan sebuah toko online factory outlet dimana didalamnya menyediakan informasi produk dan menangani pembelian secara online.

\section{METODE PENELITIAN}

Berikut merupakan kerangka pemikiran yang ada pada penelitian:

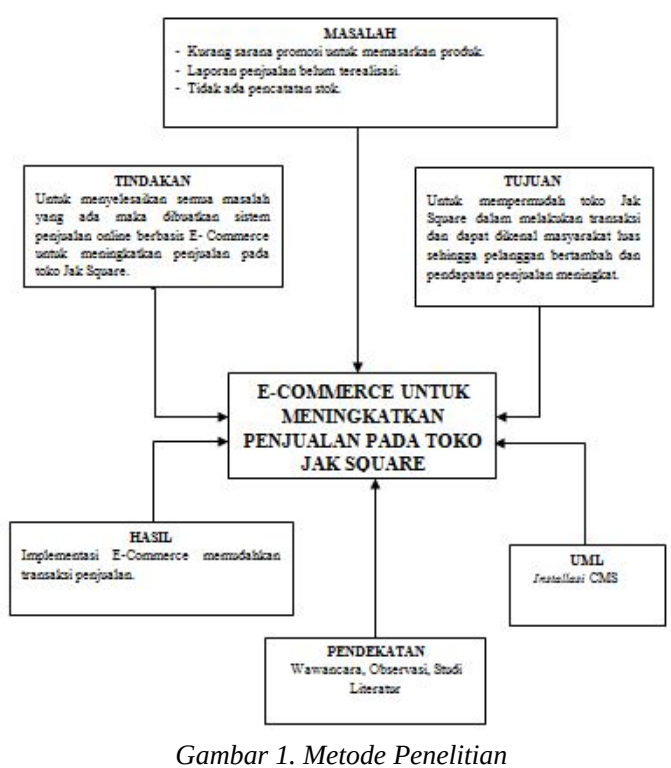

Pada gambar 1. Kerangka pemikiran yang berisikan masalah, tindakan, tujuan, hasil, uml, dan pendekatan yang ada pada penelitian.

\subsection{Wawancara}

Pada metode ini peneliti dan responden berhadapan langsung (face to face) untuk mendapatkan informasi secara lesan dengan tujuan mendapatkan data yang dapat menjelaskan permasalahan penelitian.

\subsection{Observasi}

Observasi dilaksanakan dengan melakukan pengamatan langsung terhadap proses pelaksanaan kerja dan hasil kerja yang diperoleh dan untuk menilai tingkat akurasi data dan informasi penelitian pada toko Jak Square sehingga mendapatkan data yang valid dan relevan. 


\subsection{Teknik Dokumentasi}

Teknik Dokumentasi merupakan kegiatan penelitian dengan mengamati berbagai dokumen yang berkaitan dengan topik dan tujuan penelitian.

\subsection{Studi Literatur}

Dalam metode ini penulis mencari referensi yang ada pada buku-buku yang relevan dengan masalah yang diteliti. Setelah melakukan pemahaman isi dari referensi yang didapat maka penulis dapat mengetahui kesimpulan dari hasil penelitian terdahulu.

\subsection{Analisa Sistem}

Kegiatan yang dilakukan pada tahap ini yaitu menemukan atau mengidentifikasikan masalah, mengevaluasi, membuat model serta membuat spesifikasi sistem.serta identifikasi kebutuhan. Alat yang digunakan adalah Activity Diagram dan Use Case.

\section{HASIL DAN PEMBAHASAN}

\subsection{Business Model Canvas}

Gambar 2 merupakan gambaran model konseptual yang dimiliki oleh toko Jaksquare :

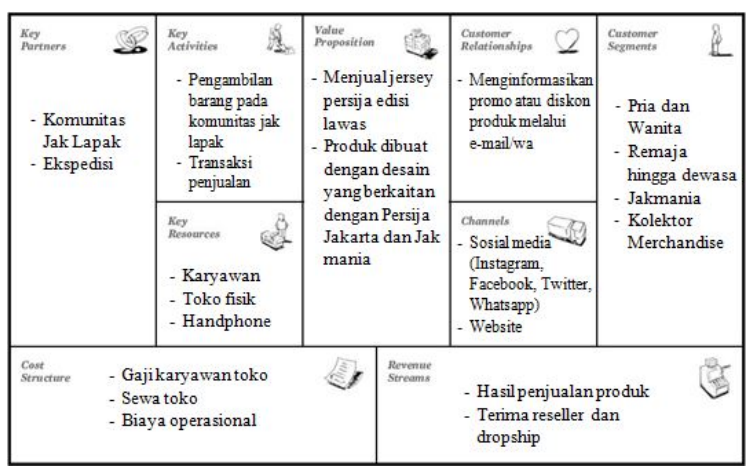

Gambar 2. Business Model Canvas

Berikut merupakan penjelasan 9 elemen blok pada gambar 2 :

a. Customer Segment

Pada blok ini menjelaskan sasaran segmentasi pelanggan dari penjualan produk pada Toko Jak Square adalah remaja hingga dewasa seperti wanita dan pria.

b. Value Propositions

Pada blok ini menjelaskan tentang keunikan dari usaha toko Jak Square, keunikan dari produk toko ini adalah menjual produk khusus supporter Persija Jakarta dengan desain yang berkaitan tentang Persija Jakarta dan Jak mania.

c. Channel

Pada blok ini merupakan media yang digunakan untuk memasarkan produk agar bisa sampai ke tangan konsumen. Media yang digunakan adalah melalui sosial media seperti whatsapp, hingga melalui website online.

d. Customer Relationship

Pada blok ini merupakan cara berinteraksi untuk menjaga loyalitas konsumen. Pada toko Jak Square ini memberikan promo atau diskon produk.

e. Revenue Streams

Pada blok ini merupakan struktur finansial dari perusahaan, produk atau jasa apa saja yang dapat memberikan pemasukan atau keuntungan dari value proposition yang ditawarkan. Keuntungan dari toko Jak Square ini didapat dari hasil penjualan produk dan juga menerima reseller dan dropship.

f. Key Activities

Pada blok ini adalah bagian yang menjelaskan bagaimana aktivitas kunci atau strategi kompetitif yang dilakukan bisnis untuk menciptakan value propositionnya. Strategi yang dilakukan pada bisnis toko Jak Square adalah pengambilan produk di komunitas jak lapak.

g. Key Resources

Pada blok ini merupakan sumber daya yang harus dimiliki perusahaan agar kompetitif dalam menciptakan value perusahaan. Sumber daya yang dibutuhkan untuk kelangsungan bisnis pada toko Jak Square adalah karyawan, toko fisik dan handphone.

h. Key Partnership

Pada blok ini erupakan mitra atau partner yang mendukung organisasi agar selalu kompetitif. Partner yang dimiliki oleh toko Jak Square ini adalah komunitas jak lapak dan ekspedisi.

i. Cost Structure

Pada blok ini merupakan biaya apa saja yang dibutuhkan untuk menjalankan keseluruhan aktivitas bisnis. Rincian biaya yang dikeluarkan pada toko Jak Square yaitu gaji karyawan toko, biaya sewa toko dan biaya operasional.

\subsection{Activity Diagram}

Activity Diagram ini menggambarkan tentang aktifitas yang terjadi pada sistem yang menunjukkan langkah-langkah dalam proses kerja sistem yang ada pada proses bisnis dan urutan aktivitas dalam sebuah proses [5]. Berikut adalah activity diagram usulan pada toko Jak Square:

a. Proses Bisnis Usulan Pendaftaran

Sebelum melakukan pemesanan pelanggan harus mengunjungi website terlebih dahulu. Setelah itu pelanggan melakukan registrasi pada menu $M y$ Account. Lalu pelanggan mengisi form registrasi kemudian klik tombol register, seperti pada gambar 3. 


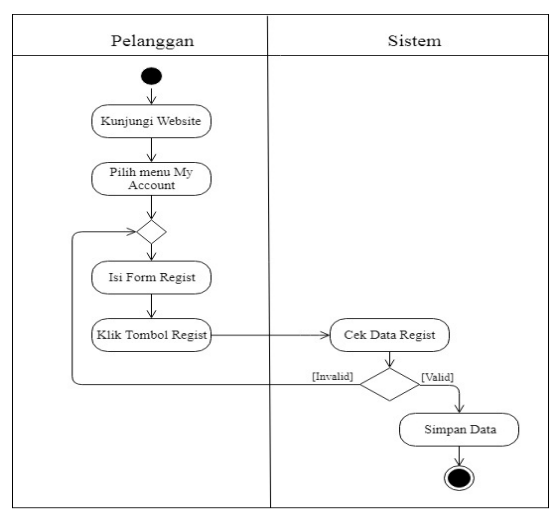

Gambar 3. Activity Diagram Sistem Usulan Proses Pendaftaran

Gambar 3 merupakan gambar activity diagram yang menjelaskan tentang proses pendaftaran.

b. Proses Pemesanan

Setelah melakukan pendaftaran pelanggan login terlebih dahulu untuk melakukan pemesanan. Kemudian pelanggan memilih produk sesuai kategori yang ada, pelanggan menentukan jumlah produk dan ukuran lalu klik add to cart. Jika pelanggan masih ingin menambah produknya, pelanggan kembali memilih produk yang diinginkan, jika tidak pelanggan klik tombol view cart untuk melihat list produk yang telah dipilih. Lalu pelanggan klik tombol checkout. Pada form checkout pelanggan mengisi form pemesanan lalu klik tombol place order. Sistem akan mengirim email new order kepada admin, seperti yang dapat dilihat pada gambar 4 dibawah.

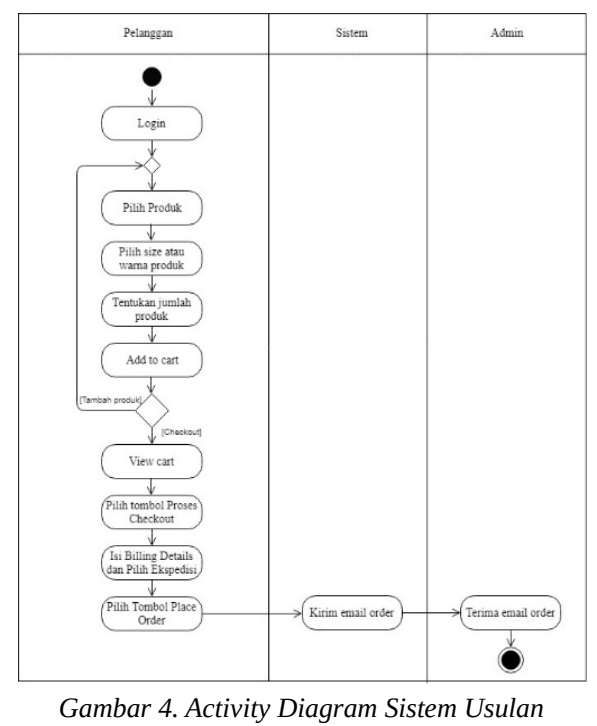

Proses Pemesanan

Gambar 4 merupakan gambar activity diagram yang menjelaskan tentang proses pemesanan.

c. Proses Pembayaran
Pelanggan melakukan pembayaran sesuai total harga yang telah dipesan. Kemudian pelanggan klik menu confirm payment untuk mengkonfirmasi pembayaran. Lalu pelanggan isi form confirm payment dan mengupload bukti transfer kemudian klik submit, seperti pada gambar 5 .

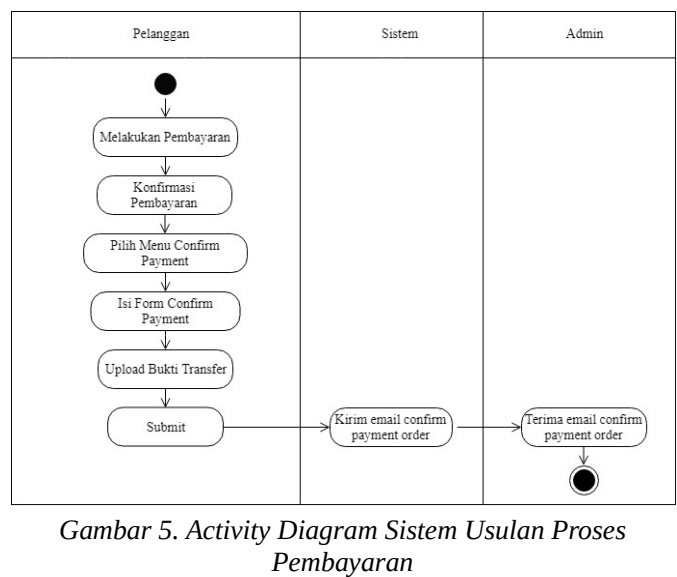

Gambar 5 merupakan gambar activity diagram yang menjelaskan tentang proses pembayaran.

d. Verifikasi Pembayaran

Admin membuka menu confirm payment untuk mengecek pembayaran, jika tidak sesuai maka admin akan mengcancel pesanan lalu sistem akan kirim email cancelled payment order kepada pelanggan, dan jika sesuai admin akan memverifikasi pembayaran pelanggan kemudian sistem kirim email payment order kepada pelanggan, seperti pada gambar 6 dibawah.

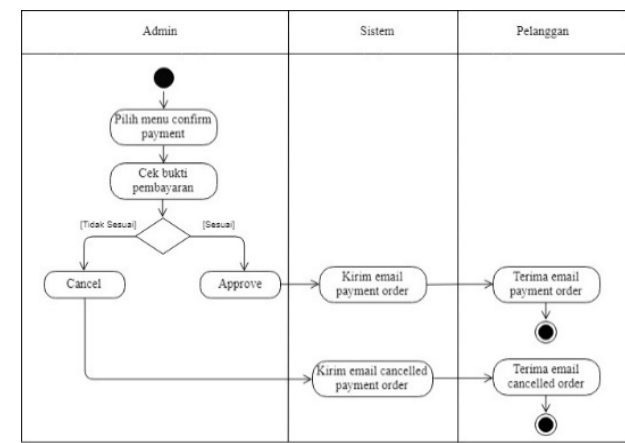

Gambar 6. Activity Diagram Sistem Usulan Verifikasi Pembayaran

Gambar 6 merupakan gambar activity diagram yang menjelaskan tentang proses verifikasi pembayaran.

e. Proses Pengiriman

Admin siapkan barang untuk dikirim dan mendapatkan resi. Setelah itu admin input resi pada menu orders lalu pilih tombol save tracking, kemudian admin update status order. Setelah itu sistem kirim email order delivered kepada pelanggan, seperti pada gambar 7 . 


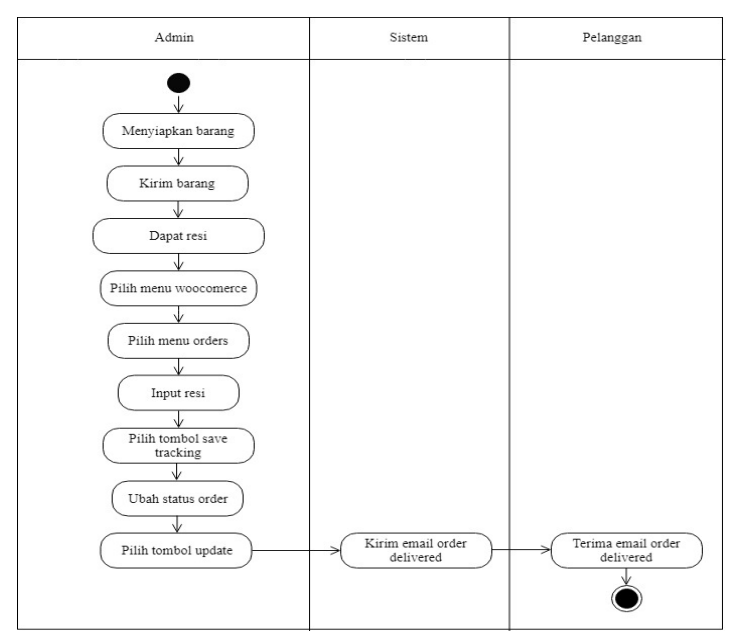

Gambar 7. Activity Diagram Sistem Usulan Proses Pengiriman

Gambar 7 merupakan gambar activity diagram yang menjelaskan tentang proses pengiriman.

f. Proses Pembuatan Laporan

Setiap bulan admin akan mencetak laporan pemesanan, laporan pengiriman, laporan pembayaran, laporan penjualan dan laporan best seller yang akan diserahkan kepada pemilik toko, seperti pada gambar 8 .

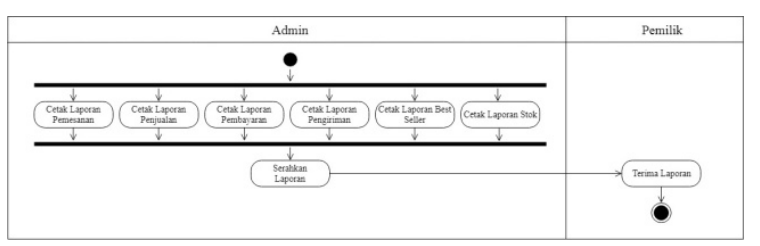

Gambar 8. Activity Diagram Sistem Usulan Proses Pembuatan Laporan

Gambar 8 merupakan gambar activity diagram yang menjelaskan tentang proses pembuatan laporan.

\subsection{Use Case Diagram}

Use case diagram adalah pemodelan untuk sistem informasi yang akan dibuat, yang menggambarkan kegiatan atau urutan interaksi yang saling berkaitan antara sistem dan actor untuk mengetahui kebutuhan diluar sistem[5]. Berikut adalah Use Case Diagram yang dibuat oleh peneliti : a. Use case diagram User

Berikut use case diagram user yang dibuat oleh peneliti.

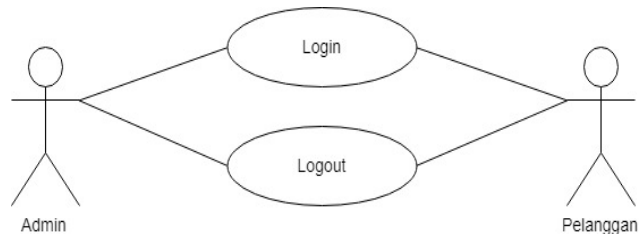

Gambar 9. Use Case Diagram User
Gambar 9 adalah use case diagram user yang terdiri dari admin dan pelanggan. Admin dan pelanggan dapat melakukan login dan logout untuk mengakses website.

b. Use Case Diagram Master

Berikut use case diagram master yang dibuat oleh peneliti.

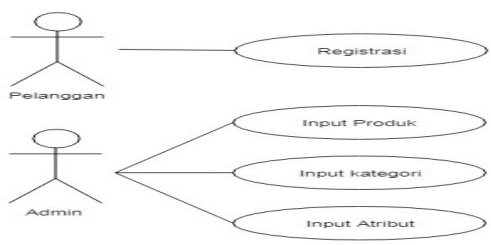

Gambar 10. Use Case Diagram Master

Gambar 10 adalah use case diagram master yang terdiri dari pelanggan dan admin. Pelanggan dapat melakukan registrasi untuk mengakses website. Admin melakukan input produk, kategori dan atribut.

c. Use Case Diagram Transaksi

Berikut use case diagram transaksi yang dibuat oleh peneliti.

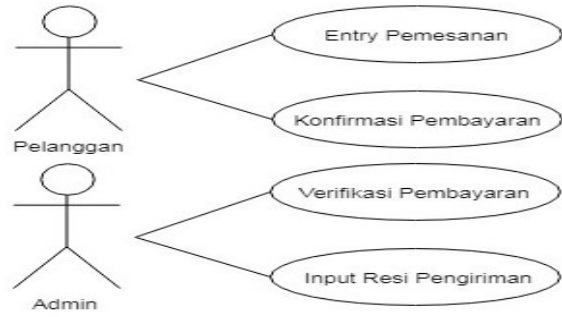

Gambar 11. Use Case Diagram Transaksi

Gambar 11 adalah use case diagram transaksi yang terdiri dari pelanggan dan admin. Pelanggan dapat melakukan entry pemesanan dan konfirmasi pembayaran. Admin dapat melakukan verifikasi pembayaran dan input resi pengiriman.

d. Use Case Diagram Laporan

Berikut use case diagram laporan yang dibuat oleh peneliti.

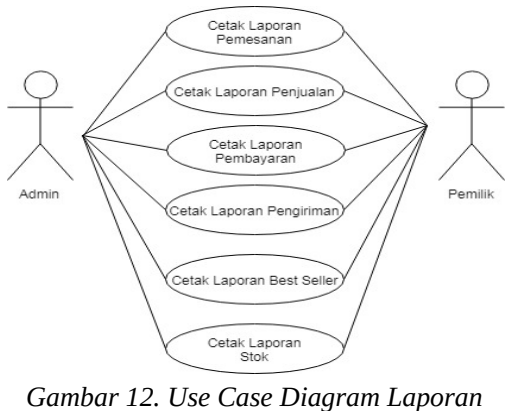

Gambar 12 adalah use case diagram laporan yang terdiri dari admin dan pemilik. Admin 
mencetak laporan pemesanan, laporan pembayaran, laporan penjualan, laporan pengiriman, laporan best seller dan laporan stok.

\subsection{System Sequence Diagram}

System Sequence Diagram (SSD) kelakuan objek pada use case dengan mendeskripsikan antara actor dan sistem[5].

a. System Sequence Diagram Regist Pelanggan

Berikut system sequence diagram regist pelanggan yang dibuat oleh peneliti.

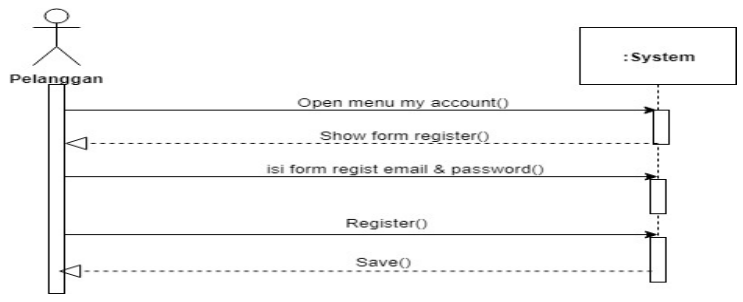

Gambar 13. System Sequence Diagram Regist Pelanggan

Gambar 13 adalah system sequence diagram yang menggambarkan uraian proses saat pelanggan ingin melakukan registrasi.

b. System Sequence Diagram Entry Pemesanan

Berikut system sequence diagram entry pemesanan yang dibuat oleh peneliti.

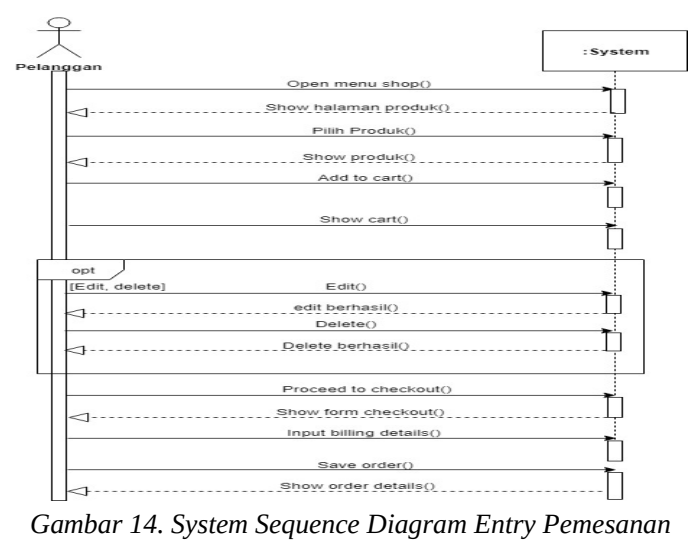

Gambar 14 adalah system sequence diagram yang menggambarkan kegiatan pelanggan pada saat melakukan pemesanan.

c. System Sequence Diagram Laporan Pemesanan

Berikut system sequence diagram laporan pemesanan yang dibuat oleh peneliti.

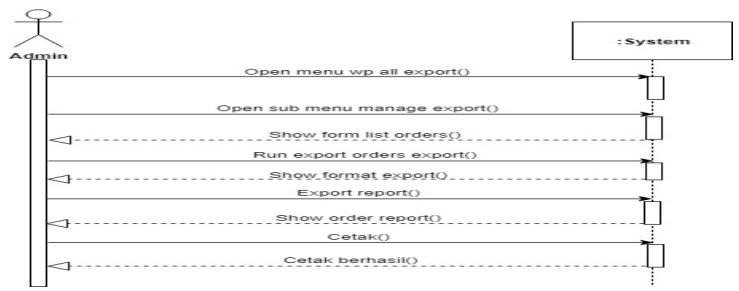

Gambar 15. System Sequence Diagram Entry Pemesanan
Gambar 15 adalah system sequence diagram yang menggambarkan kegiatan admin pada saat ingin mencetak laporan pemesanan.

\subsection{Tampilan Layar}

a. Tampilan Halaman Utama Website

Berikut tampilan halaman utama website yang dibuat oleh peneliti.

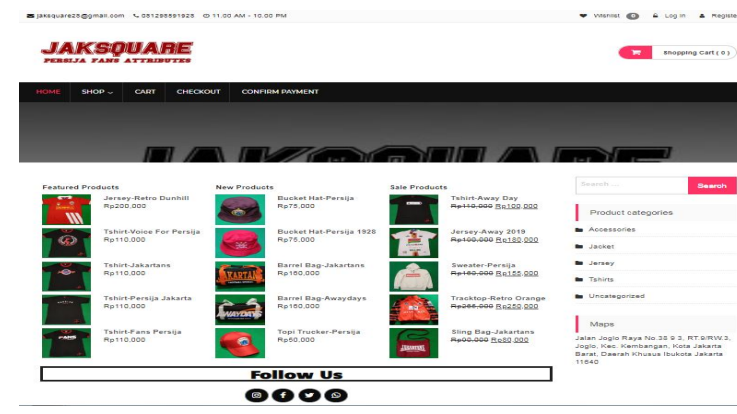

Gambar 16. Tampilan Halaman Utama Website

Gambar 16 merupakan tampilan layar pada halaman utama website jaksquare.

b. Tampilan Delivered Order

Berikut ini tampilan delivered order yang ada pada toko jaksquare.

\section{Thanks for shopping with us}

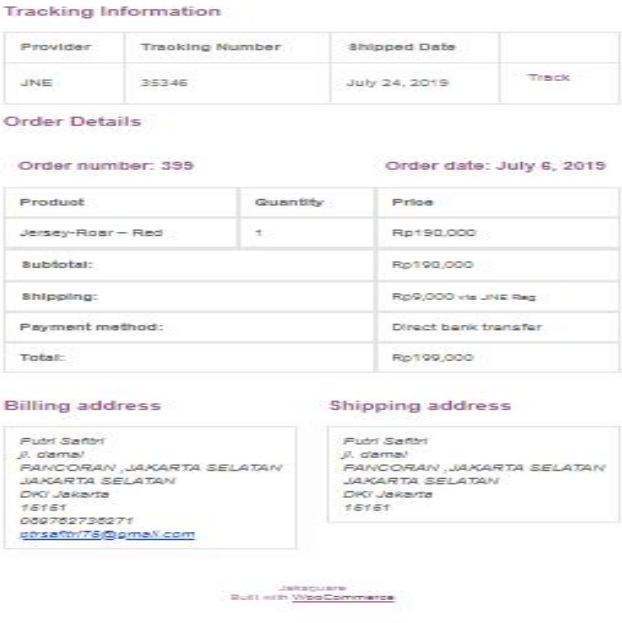

Gambar 17. Tampilan Invoice Delivered Order

Gambar 17 merupakan tampilan delivered order yang diterima pelanggan untuk menginformasikan bahwa barang telah dikirim.

c. Tampilan Laporan Pemesanan

Berikut ini tampilan laporan pemesanan yang ada pada toko jaksquare. 


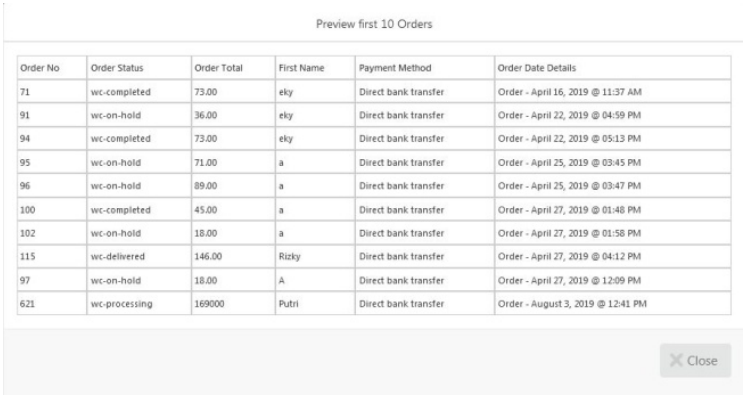

Gambar 18. Tampilan Laporan Pemesanan

Gambar 18 merupakan tampilan layar pada saat mencetak laporan pemesanan.

\section{KESIMPULAN}

1. Dengan adanya website e-commerce ini dapat membantu toko dalam meningkatkan pemasaran produk dan toko dapat dikenal oleh masyarakat luas.

2. Dengan adanya website e-commerce customer dapat langsung melihat produk terbaru yang ditawarkan tanpa adanya batasan waktu dan tempat.

\section{DAFTAR PUSTAKA}

[1] Yunita, I., \& Suryani, L. Perancangan E-Commerce Batik Pada Batik Banten. 1(2), 2018, 66-81.

[2] Syamsuddin, I., \& Nur, R. Pemanfaatan cms open source pada lembaga dakwah, 2017, 357-360.

[3] Priska, L., \& Harjanti, D. Strategi Pengembangan Bisnis Pada Depot Selaris Dengan Pendekatan Business Model Canvas, 3(2), 2015, 292-301.

[4] Haryanti, S., \& Irianto, T., Rancang Bangun Sistem Informasi E-Commerce Untuk Usaha Fashion Studi Kasus Omah Mode Kudus, 3(1), 2011, 8-14.

[5] Hendini, A. Pemodelan UML Sistem Informasi Monitoring Penjualan Dan Stok Barang (Stidu Kasus: Distro Zhezha Pontianak), IV(2), 2016, 107116. 